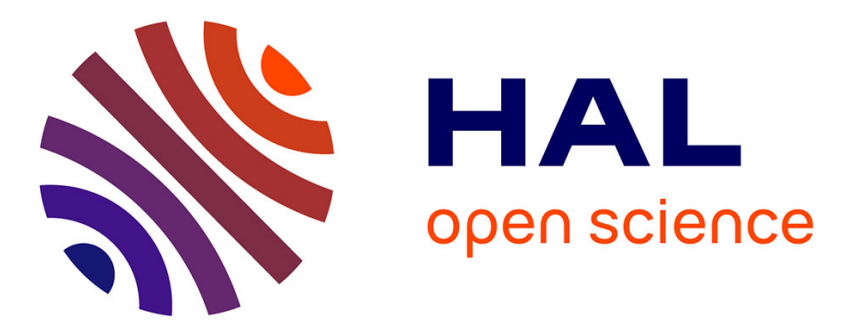

\title{
Stimulated infrared emission from rocks: assessing a stress indicator
}

F. T. Freund, A. Takeuchi, B. W. S. Lau, A. Al-Manaseer, C. C. Fu, N. A. Bryant, D. Ouzounov

\section{- To cite this version:}

F. T. Freund, A. Takeuchi, B. W. S. Lau, A. Al-Manaseer, C. C. Fu, et al.. Stimulated infrared emission from rocks: assessing a stress indicator. eEarth, 2007, 2 (1), pp.7-16. hal-00298232

\section{HAL Id: hal-00298232 \\ https://hal.science/hal-00298232}

Submitted on 10 Jan 2007

HAL is a multi-disciplinary open access archive for the deposit and dissemination of scientific research documents, whether they are published or not. The documents may come from teaching and research institutions in France or abroad, or from public or private research centers.
L'archive ouverte pluridisciplinaire HAL, est destinée au dépôt et à la diffusion de documents scientifiques de niveau recherche, publiés ou non, émanant des établissements d'enseignement et de recherche français ou étrangers, des laboratoires publics ou privés. 


\title{
Stimulated infrared emission from rocks: assessing a stress indicator
}

\author{
F. T. Freund ${ }^{1,2}$, A. Takeuchi ${ }^{2,3}$, B. W. S. Lau $^{2}$, A. Al-Manaseer ${ }^{4}$, C. C. Fu ${ }^{5}$, N. A. Bryant ${ }^{6}$, and D. Ouzounov ${ }^{7}$ \\ ${ }^{1}$ Ecosystems Science and Technology Branch, Code SGE, NASA Ames Research Center, Moffett Field, CA 94035-1000, \\ USA \\ ${ }^{2}$ Department of Physics, San Jose State University, San Jose, CA 95192-0106, USA \\ ${ }^{3}$ Department of Chemistry, Niigata University, Ikarashi-ninotyo, Niigata 950-2181, Japan \\ ${ }^{4}$ Department of Civil Engineering, San Jose State University, San Jose, CA 95192-0083, USA \\ ${ }^{5}$ Department of Civil Engineering, University of Maryland, College Park, MD 20742, USA \\ ${ }^{6}$ Jet Propulsion Laboratory, Org. 3880, Pasadena, CA 91109-8099, USA \\ ${ }^{7}$ CEORS, George Mason University, Fairfax, VA 22030-4444, USA
}

Received: 16 May 2006 - Published in eEarth Discuss.: 24 July 2006

Revised: 7 November 2006 - Accepted: 13 December 2006 - Published: 10 January 2007

\begin{abstract}
To study the effect of stress-activated positive hole (p-hole) charge carriers on the infrared (IR) emission from rocks, we subjected a portion $(\sim 10 \mathrm{vol} . \%)$ of a large $\left(30 \times 60 \times 7.5 \mathrm{~cm}^{3}\right)$ block of anorthosite, a nearly monomineralic (Ca-rich feldspar) igneous rock, to uniaxial deviatory stress up to failure. We measured the IR emission from a flat surface $\approx 40 \mathrm{~cm}$ from the stressed rock volume over the $800-1300 \mathrm{~cm}^{-1}(7.7-12.5 \mu \mathrm{m})$ range. Instantly, upon loading, the emission spectrum and intensity change. At first narrow bands appear at $930 \mathrm{~cm}^{-1}(10.75 \mu \mathrm{m}), 880 \mathrm{~cm}^{-1}$ $(11.36 \mu \mathrm{m}), 820 \mathrm{~cm}^{-1}(12.4 \mu \mathrm{m})$ plus additional narrow bands in the $1000-1300 \mathrm{~cm}^{-1}(7.7-10.0 \mu \mathrm{m})$ range. The $10.75-12.4 \mu \mathrm{m}$ bands are thought to arise from vibrationally excited O-O stretching modes, which form when p-hole charge carriers, which spread from the stressed rock volume into the unstressed rock, recombine at the surface. They radiatively decay, giving rise to "hot" bands due to transitions between excited states. Before failure the broad emission bands at $1170 \mathrm{~cm}^{-1}$ and $1030 \mathrm{~cm}^{-1}(8.7$ and $9.7 \mu \mathrm{m})$ also increase slightly in intensity, suggesting a small increase in temperature due to thermalization of the energy deposited into the surface through p-hole recombination. Stimulated IR emission due to hole-hole recombination and its followon effects may help understand the enhanced IR emission seen in night-time satellite images of the land surface before major earthquakes known as "thermal anomalies".
\end{abstract}

Correspondence to: F. T. Freund

(ffreund@mail.arc.nasa.gov)

\section{Introduction}

In this paper we describe a laboratory experiment that may help understand the cause for the non-stationary, transient areas of enhanced IR emission from the land surface, which have been recognized since the late 1980s and early 1990s in night-time satellite images and linked to impending earthquake activity (Gornyi et al., 1988; Qiang et al., 1991, 1990; Srivastav et al., 1997). The reported increase in surface temperatures reach $2-4^{\circ} \mathrm{C}$, occasionally higher. Such areas of enhanced IR emission are referred to as "thermal anomalies".

The phenomenon of thermal anomalies has remained enigmatic (Cui et al., 1999; Srivastav et al., 1997; Tronin, 2000, 2002; Tronin et al., 2004). In many cases the reported increase in temperature seems to correlate poorly with meteorological ground data. The rapidity with which the thermal anomalies appear and disappear rules out that they are caused by a flow of Joule heat from a source deep below that would heat the rocks. Several other processes have been invoked to account for the reported temperature increase: (i) rising fluids that could lead to the emanation of warm gases (Gorny et al., 1998); (ii) rising well water levels and changing moisture contents in the soil (Chadha et al., 2003); (iii) diffuse $\mathrm{CO}_{2}$ emanation, causing a "local greenhouse" effect (Quing et al., 1991; Tronin, 1999, 2002); (iv) Near-ground air ionization due to enhanced radon emission leading to the condensation of water vapor from the atmosphere and, hence, to the release of latent heat (Pulinets et al., 2005). However, at closer inspection, none of these explanations seem to be able to adequately account for characteristic features of the "thermal anomalies".

Here we report on a laboratory experiment conducted to test a very different hypothesis: could it be that the enhanced

Published by Copernicus GmbH on behalf of the European Geosciences Union. 


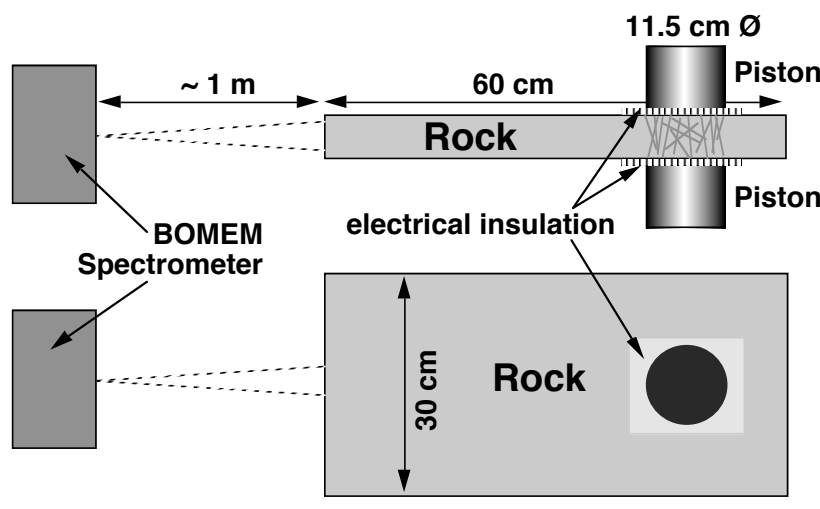

Fig. 1a. Schematic of the set-up used to measure the IR emission from the flat front face of a $60 \times 30 \times 7.5 \mathrm{~cm}^{3}$ block of anorthosite, loaded over $40 \mathrm{~cm}$ away from the emitting rock surface.

IR emission from the Earth's surface arises from electronic charge carriers from deep within the Earth's crust when rocks are subjected to increasing stresses prior to large earthquakes? We know that such electronic charge carriers are activated by stress and that they are highly mobile (Freund, 2002). We know that they diffuse rapidly to the surface where they become trapped (Freund et al., 2006; Takeuchi et al., 2006). The question that we seek to answer by our experiment is: do these electronic charge carriers recombine at the rock surface leading to a diagnostically distinct IR emission in the region of the thermal infrared?

\section{Experimental part}

Our sample was a block of anorthosite from Larvik, Norway, available under the trade name "Blue Pearl". Anorthosite is an igneous monomineralic feldspar rock composed mainly of Ca-rich plagioclase labradorite. The rock we used was coarse-grained with crystals up to $2-4 \mathrm{~cm}$ in size with a density of $2.7 \mathrm{~g} / \mathrm{cm}^{3}$ and an unconstrained compressive strength of 181-187 MPa.

We uniaxially stressed a relatively small subvolume, 10 $12 \mathrm{vol} . \%$, of an air-dry anorthosite slab, $60 \times 30 \times 7.5 \mathrm{~cm}^{3}$, via a pair of pistons $(11.25 \mathrm{~cm}$ diameter), electrically insulated from the rock through $0.8 \mathrm{~mm}$ thick sheets of high density polyethylene with a resistivity of $>10^{14} \Omega \mathrm{cm}$. We applied the load off-center as sketched in Fig. 1a, about one piston diameter away from the edges and about four piston diameters $(>40 \mathrm{~cm})$ away from the surface, which emitted the IR radiation measured during our experiment. Figure $1 \mathrm{~b}$ depicts the distribution of the principal stress as obtained by finite element analysis. The off-center loading concentrated the stresses in the back portion of the slab and kept the emitting front surface of the slab essentially stress-free, especially during the early phase of the loading run when the absolute stresses are still relatively small. We applied the load at a

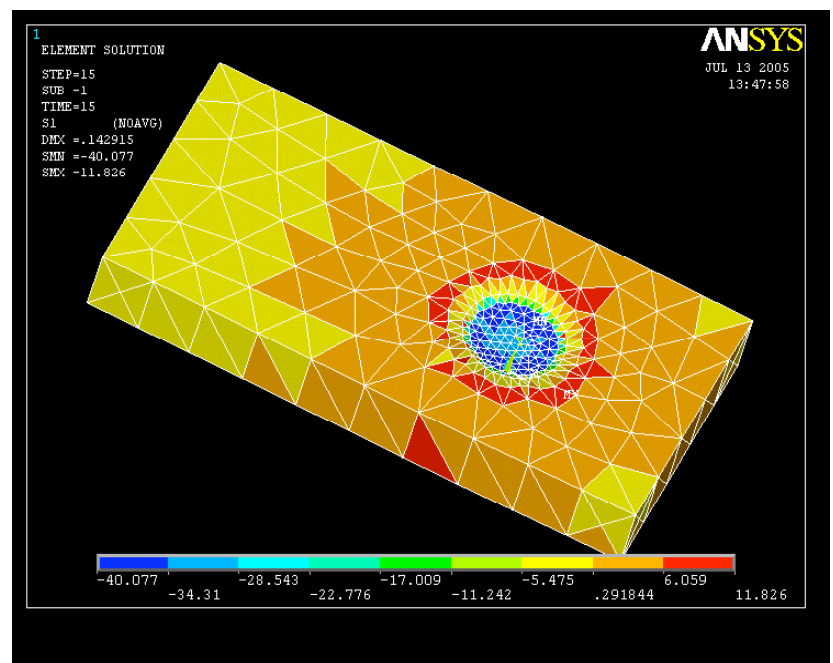

Fig. 1b. Finite analysis representation, using a variable grid size, of the stress distribution in the anorthosite block during asymmetric loading. Yellow to blue signify compressive stresses, yellow to red tensile stresses. The surface from where the IR emission is measured (circular, $5 \mathrm{~cm}$ diameter, $\sim 20 \mathrm{~cm}^{2}$ ) is on the hidden surface on the upper left.

constant rate of $6.3 \mathrm{MPa} / \mathrm{min}$ up to failure, using a hydraulic SATEC press, model RD $2000 \mathrm{kN}$.

Emission spectra were recorded off a circular area, $5 \mathrm{~cm}$ diameter, from the flat front face of the rock, smooth "as received", i.e. as cut with a diamond saw. We used a Bomen MB-100 FT-IR spectroradiometer equipped with a Peltiercooled $\mathrm{HgCdTe}$ detector and two integrated blackbody emitters for internal calibration, one at ambient temperature, the other at $60^{\circ} \mathrm{C}$, collecting the IR radiation sequentially from the sample and the two blackbody emitters. This Bomen MB-100 has been used extensively for laboratory and field calibrations for NASA's MODIS spectrometers currently flying on the TERRA and AQUA satellites (Li et al., 1999; Wan et al., 1996).

During our experiment the laboratory was semi-darkened. The space between rock and spectroradiometer, about $1 \mathrm{~m}$, was shielded from ambient light. The temperature in the laboratory was stable. As an additional precaution the movement of all personnel during the $36 \mathrm{~min}$ long run was restricted to avoid changes in the reflected IR radiation field.

The spectra were recorded over the wavenumber range $700-1400 \mathrm{~cm}^{-1}(7.14-14.25 \mu \mathrm{m})$ at $2 \mathrm{~cm}^{-1}$ resolution. Each FT-IR file consists of 25 scans off the rock surface plus 5 scans off the ambient temperature blackbody and 5 scans off the $60^{\circ} \mathrm{C}$ blackbody emitters for temperature calibration. It took $40 \mathrm{~s}$ to acquire and store each file. The radiometric noise at the single scan level was $\sim 100 \mathrm{mK}$, improving to $\sim 50 \mathrm{mK}$ upon averaging 25 scans and to $\sim 10 \mathrm{mK}$ upon averaging 250 scans. The run lasted a total $2200 \mathrm{~s}(36 \mathrm{~min} 40 \mathrm{~s})$, during which 250 scans or 10 files were recorded during the first $400 \mathrm{~s}(6 \mathrm{~min} 40 \mathrm{~s})$ without applying a load. 


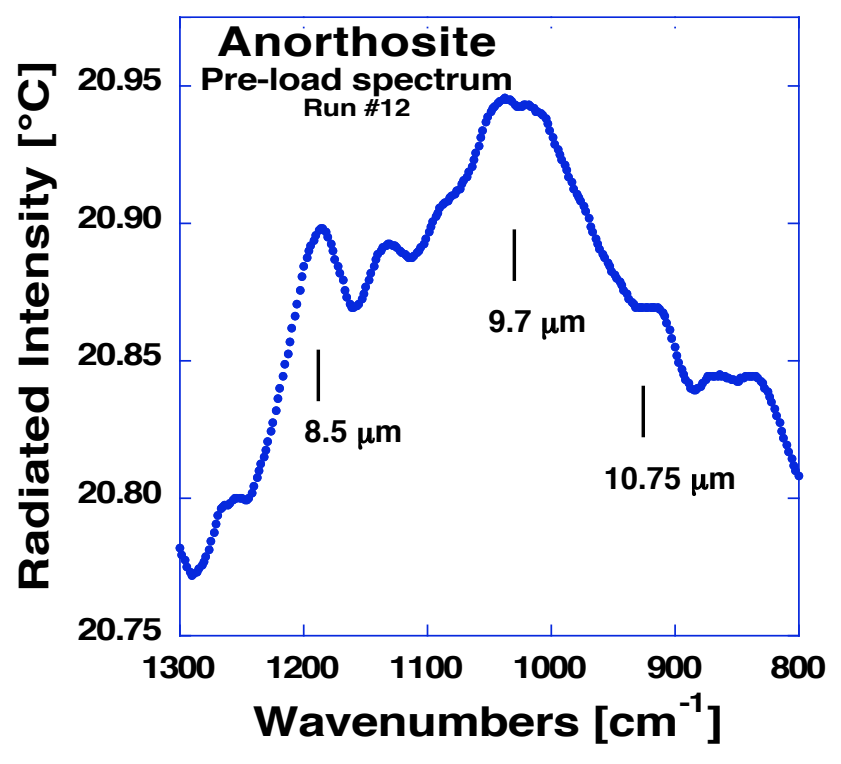

Fig. 2. IR emission spectrum at room temperature (average of 10 files of 25 scans each) from the flat front surface of the anorthosite block before loading.

The IR flux emitted from the rock surface was calculated in brightness temperature $\mathrm{T}_{B}$ with reference to the builtin calibration emitter surfaces, using the same algorithm as for MODIS calibration runs. $\mathrm{T}_{B}$ is an energy scale widely used in remote sensing, where the intensity at frequency $v$ is defined as $\mathrm{I}_{v}=\mathrm{B}_{v}\left(\mathrm{~T}_{B}\right)$ with $\mathrm{B}_{v}$ in units of [Joule $\mathrm{s}^{-1} \mathrm{~m}^{-1}$ ster ${ }^{-1} \mathrm{~Hz}^{-1}$ ] given as $\mathrm{B}_{v} \approx 2 v^{2} \mathrm{kT}_{B} / \mathrm{c}^{2}$, with $\mathrm{k}$ the Boltzmann constant, $\mathrm{T}_{B}$ the absolute temperature, and $\mathrm{c}$ the speed of light. Expressing $\mathrm{T}_{B}$ in terms of wavelength $\lambda$, we obtain $\mathrm{T}_{B} \approx\left[\lambda^{4} / 2 \mathrm{kc}\right] \mathrm{I}_{\lambda}$. This relation shows that, while $\mathrm{T}_{B}$ depends on the fourth power of the wavelength of the emitted light, changes in the actual (Joule) temperature will cause smooth intensity changes over the entire spectral range.

\section{Results}

Figure 2 shows the pre-loading room temperature (300 K) IR emission spectrum of the anorthosite from 800 to $1300 \mathrm{~cm}^{-1}$ (7.7-12.5 $\mu \mathrm{m})$, averaged from the 250 pre-loading scans (10 files). The spectrum has two maxima, around 1030 and $1170 \mathrm{~cm}^{-1}$ (9.7 and $8.5 \mu \mathrm{m}$, respectively), plus a smaller emission peak around $1110 \mathrm{~cm}^{-1}(9.0 \mu \mathrm{m})$. These bands are characteristic of $\mathrm{Si}-\mathrm{O}$ and $\mathrm{Al}-\mathrm{O}$ stretching modes emitted from the first few $\mu \mathrm{m}$ of the rock surface (Johnson et al., 2002). This room temperature emission is caused by downward transitions of 3-dimensionally coupled $\mathrm{Si}-\mathrm{O}$ and $\mathrm{Al}-\mathrm{O}$ stretching modes, primarily from their populated first vibrationally excited states thermally at $300 \mathrm{~K}$, e.g. from quantum number $\mathrm{n}=1$, to the ground state $\mathrm{n}=0$.

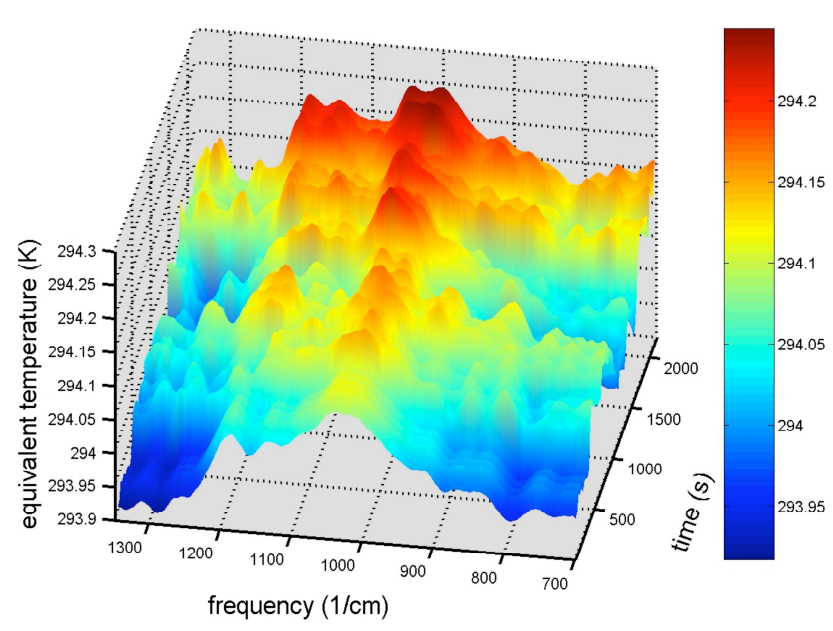

Fig. 3a. 3-D plot of the intensity evolution and spectral changes of the IR emission between $700-1350 \mathrm{~cm}^{-1}(7.37-14.3 \mu \mathrm{m})$ from the front face of the anorthosite block before and during loading up to failure, plotted as a function of time during loading (for details see text). The color scale is given in degrees $\mathrm{K}$ and is meant to emphasize the changing intensities.

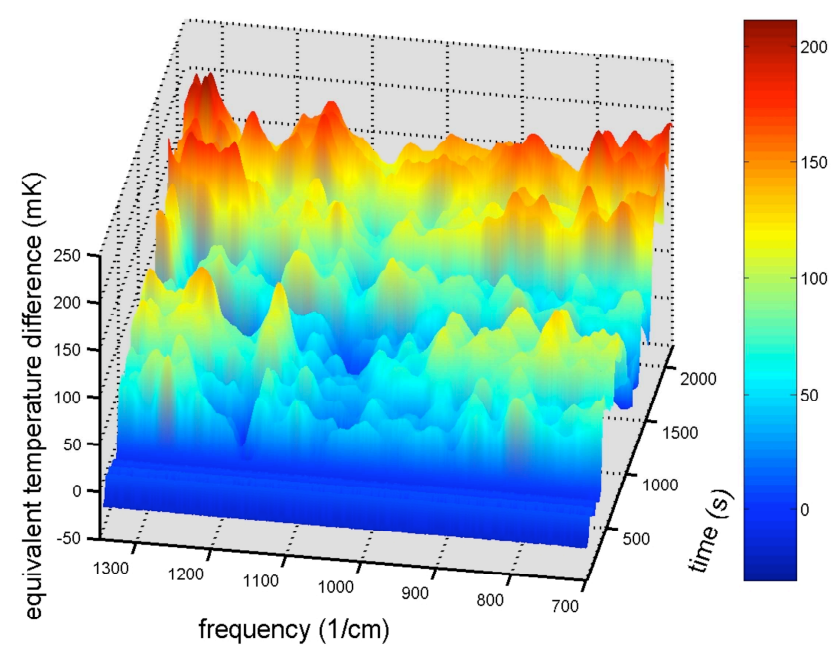

Fig. 3b. Difference plot of the intensity evolution and spectral changes of the IR emission from the front face of the anorthosite block obtained by subtracting each file recorded during loading from the average of the pre-load files. The color scale is given in degrees $\mathrm{mK}$ and is meant to emphasize the changing excess intensities.

Figure 3a shows a 3-D plot of the intensity variations over the $7.4-14.3 \mu \mathrm{m}$ range (700 to $1350 \mathrm{~cm}^{-1}$ ) as a function of time. The intensity axis is given in units of brightness temperature, $\mathrm{T}_{B}$. The time axis is labeled in seconds. During the first $6 \mathrm{~min} 40 \mathrm{~s}$, as we acquired 250 pre-load scans (10 files) with no stress applied, the emitted IR intensity is constant. This is consistent with a stable ambient temperature environment in the laboratory and the absence of any other 


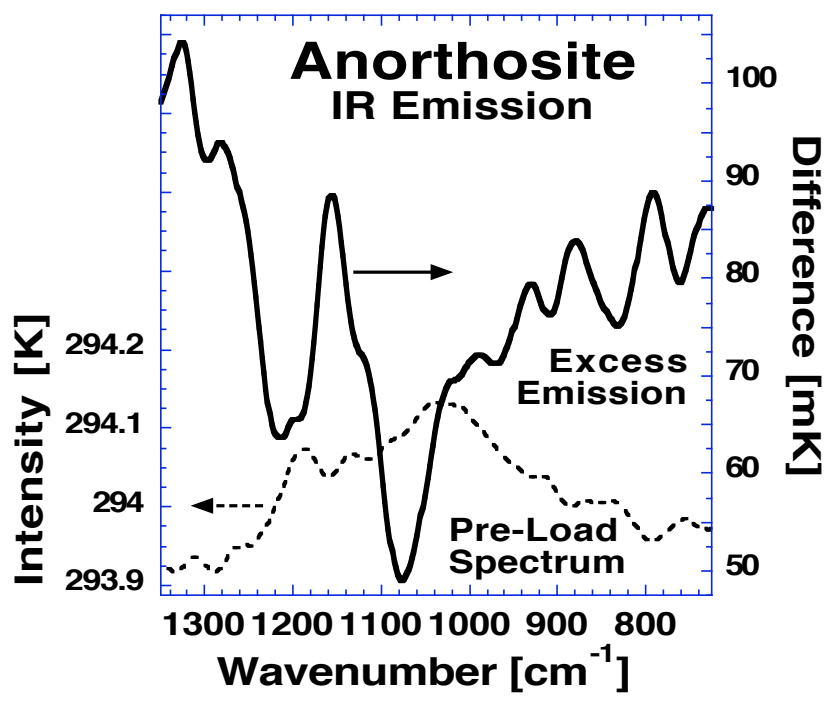

Fig. 4. Total excess intensity emitted over the 7.37-14.7 $\mu \mathrm{m}$ range from the front face of the anorthosite block during loading (solid line) compared to the pre-load spectrum (dotted line).

perturbations. After $6 \mathrm{~min} 40 \mathrm{~s}$ we began to apply the load and immediately saw a change in the spectral signature, in particular new narrow emission bands, plus an overall increase in IR intensity. Upon increasing the load, the intensities fluctuate. Such fluctuations had already been observed during earlier IR emission experiments with granite (Freund et al., 2002b, 2003). The IR intensity fluctuations resemble current fluctuations observed during measurements of "battery currents", which flow out of a stressed rock volume through the unstressed rock (Freund et al., 2004, 2006).

The difference spectra in Fig. 3b show the excess intensity emitted over the spectral range as a function of time. The difference spectra were obtained by subtracting the average of the first 250 pre-load scans (10 files) from each of the files acquired during loading up to failure. There are three outstanding features:

1. Narrow emission bands appear immediately upon loading, specifically three bands in the $800-950 \mathrm{~cm}^{-1}$ range $(10.5-12.5 \mu \mathrm{m})$ plus narrow bands at higher wavenumbers (shorter wavelengths).

2. The intensity fluctuations as a function of time are synchronous across the entire spectral range, though the fluctuations of different bands are not evenly distributed.

3. The excess intensity emitted during loading is concentrated at wavelengths that are different from those of the two emission maxima in the pre-load emission spectrum.

This last point is highlighted in Fig. 4 where we superpose the pre-load $300 \mathrm{~K}$ spectrum and the excess IR inten- sity integrated over the entire run. The narrow emission bands are preserved even after integration, in particular the three diagnostically significant bands in the $800-950 \mathrm{~cm}^{-1}$ $(10.5-12.5 \mu \mathrm{m})$ range, plus a prominent narrow band around $1150 \mathrm{~cm}^{-1}(8.7 \mu \mathrm{m})$. While the pre-load spectrum exhibits intensity maxima at $1030 \mathrm{~cm}^{-1}$ and $1170 \mathrm{~cm}^{-1}(9.7$ and $8.5 \mu \mathrm{m})$, the excess emission has minima near these same wavenumber/wavelength values.

During two earlier measurement sessions with granite we already had the opportunity of record the IR emission from the surface of a large block of rock stressed a distance away from the emitting surface. We observed similar spectral features, in particular narrow emission bands at the start of loading (Freund et al., 2002a, 2003). Granite contains about 1/3 quartz, 1/3 plagioclase feldspar and 1/3 potassium feldspar. Similar to the observation reported here, excess IR was emitted in narrow bands in the $800-950 \mathrm{~cm}^{-1}(10.5-12.5 \mu \mathrm{m})$ range plus some bands in the $1150 \mathrm{~cm}^{-1}(8.7 \mu \mathrm{m})$ range. The present results confirm these earlier observations, though the narrow emission bands from granite occurred at slightly different wavenumbers, within $\sim 10 \mathrm{~cm}^{-1}$, probably due to its more complex mineralogy.

\section{Discussion}

Rock fracture experiments as described in the literature are typically performed under conditions emulating ASTM C170-50 and DIN 52102 procedures, i.e. with cylindrical test samples loaded over their entire cross section (Brady and Rowell, 1986; Lockner, 1993; Rowell et al., 1981; Warwick et al., 1982; Yoshida and Ogawa, 2004).

Loading unconstrained cylindrical samples over their entire cross sections creates conditions that are very different from those described here and different from pre-earthquake conditions in the field. In the field, the rocks deep in the Earth's crust are subjected to increasing stress, while observations are made off the Earth's surface, far from the stressed rock volume. In the experiment described here we subject a relatively small subvolume of the large rock sample to deviatory stresses, thereby activating mobile electronic charge carriers. We thus create a gradient in the concentration of these charge carriers between the subvolume and the surrounding unstressed rock. No mechanical forces act on the surface from where the IR emission occurs. In the case of cylinders loaded over their entire cross section, the surface bulges outward, leading to tensile stresses in the surface, which in turn lead to microfracturing. Microfracturing is known to cause visible and IR emission over a broad spectral range (Brady and Rowell, 1986) due to a number of physical processes that take place in the opening cracks such as electric discharges, electron and atom or molecule emissions, ionization and electronic excitations, etc. (Dickinson, et al., 1986). Only the stressed rock volume emits light during these processes and the spectral composition of this light 
is very different from the narrow band IR emission reported here.

The experiment presented here was designed from the beginning in such a way that the stresses generated during loading would be confined to the back portion of the slab and would not extend to the surface that emitted the IR emission radiation. Because of the large distance between the emitting surface and the stressed rock volume, $>40 \mathrm{~cm}$, we can rule out that frictional heat generated in the stressed rock could diffuse to the emitting surface within $40 \mathrm{~s}$, the time needed to acquire 25 scans with the Bomen FT-IR spectroradiometer and to convert them into one file. Hence, under our conditions, the IR emission from the front surface of the block, cannot be due to Joule heat diffusing from the stressed subvolume to the emitting surface.

Another possibility is that, upon loading the subvolume, gases and possibly liquids contained in its pore space might be expelled and travel as a pressure wave through the pore space in the remainder of the rock, inducing rapid changes far from the stressed subvolume. However, we can discount this process on the basis of two arguments: (i) given the geometry of our rock sample and stress distribution illustrated by Fig. 1b, such a pressure wave, if it forms, would more likely discharge through the near-by surfaces under tensile stress rather than travel to the surface furthest from the stress subvolume; (ii) even if the pressure wave arrives at the emitting surface, it would more likely cool the surface through adiabatic decompression than cause the emission of excess IR intensity in the form of specific narrow bands.

Neither diffusion of frictional heat to the rock surface nor the arrival of a pore gas pressure wave can account for observed changes in the IR emission characteristics. Hence we conclude that there must be another process capable of transporting energy rapidly from the stressed rock subvolume to the rock surface, over a distance of $>40 \mathrm{~cm}$, and of causing the observed changes, both spectral and intensitywise, in the IR emission.

A candidate for such a process, for which we have strong supporting evidence, is the flow of electronic charge carriers from the stressed subvolume to the rock surface. Such charge carriers have been shown to exist in igneous rocks such as anorthosite, albeit in a dormant, electrically inactive form (Freund, 2002; Freund et al., 2006, 2004). In the following we briefly review what these charge carriers are and what is already known about them.

It is widely assumed in the geoscience community that oxygen anions in naturally occurring minerals are fixed in their 2-valence state. However, it has been shown some time ago that a reaction exists by which oxygen anions can change their valence from 2- to 1- (Freund and Wengeler, 1982; Martens et al., 1976). The reaction involves hydroxyl pairs, which are ubiquitous in all minerals that have crystallized in the presence of $\mathrm{H}_{2} \mathrm{O}$, even those that are nominally anhydrous. Hydroxyl pairs in the matrix of these nominally an- hydrous minerals can split off $\mathrm{H}_{2}$ while simultaneously converting their $\mathrm{O}^{2-}$ to the 1- (peroxy) state (Freund, 1985).

A single $\mathrm{O}^{-}$in a matrix of $\mathrm{O}^{2-}$ represents a defect electron, resident in the valence band of otherwise insulating materials, also known as a positive hole or p-hole for short. Normally $\mathrm{O}^{-}$form pairs, which we call positive hole pairs, PHP. In oxide materials the PHPs form peroxy anions, $\mathrm{O}_{2}^{2-}$ (Batllo et al., 1991; Freund et al., 1993). In silicate minerals they form peroxy links, $\mathrm{O}_{3} \mathrm{X} /{ }^{\mathrm{OO}} \backslash \mathrm{XO}_{3}$ with $\mathrm{X}=\mathrm{Si}^{4+}, \mathrm{Al}^{3+}$ etc. Peroxy links in fused silica have attracted a large amount of attention because, when present in fused silica optical fibers exposed to high energy $\gamma$ - or x-rays in space, they lead to color centers with an intense, broad absorption in the visible and near-IR regions (Edwards and Fowler, 1982; Ricci et al., 2001). The same peroxy links in fused silica generate mobile p-hole charge carriers when heated (Freund, 1985). Minerals that crystallize in the presence of $\mathrm{H}_{2} \mathrm{O}$ invariably always incorporate some "water" in the form of hydroxyl (Ingrin and Skogby, 2000; Wilkins and Sabine, 1973). Hydroxyl pairs in the matrix of these minerals are thought to convert to peroxy links (Freund, 1985). This makes all igneous and high-grade metamorphic rocks candidates for containing PHPs (Freund, 2003).

As long as the $\mathrm{O}^{-}$exist in the PHP or peroxy state, the p-holes are self-trapped and, hence, electrically inactive. When deviatory stresses are applied, the rocks begin to plastically deform through dislocations moving in large numbers through the mineral grains (Miguel et al., 2001; Moore and Lockner, 1995; Ohnaka, 1995). When moving dislocations intersect the PHPs, they instantly cause them to break apart and to release p-hole charge carriers (Freund et al., 2006).

As defect electrons in the valence band of the otherwise insulating silicate minerals the p-holes can move on the $\mathrm{O} 2 \mathrm{sp}$ dominated levels close to the upper edge of the valence band by exchanging an electron with a neighboring $\mathrm{O}^{2-}$. Theoretically the speed with which the p-holes could travel is on the order of $300 \mathrm{~m} / \mathrm{s}$, consistent with the group velocities in the range of $100-300 \mathrm{~m} / \mathrm{s}$ measured experimentally (Freund, 2002). Because the valence band forms an energetic continuum the p-holes can jump grain boundaries. In experiments such as described here, where we stress a portion of a larger slab of rock, the p-holes can flow out of the stressed volume and into unstressed rock (Freund et al., 2006). When they reach the surface, they form a positive charge layer (Freund et al., 1993; King and Freund, 1984). Positive surface charges have also been observed during fracturing (Enomoto et al., 1993). Surface potentials measured under open circuit conditions can reach $+1.5 \mathrm{~V}$ to $+1.75 \mathrm{~V}$. Charge densities on freshly fracture surfaces have been given as $10^{-5} \mathrm{Coulomb} / \mathrm{m}^{2}$ or $10^{13}-10^{14} \mathrm{p}$-holes $/ \mathrm{m}^{2}$ (Takeuchi et al., 2006; Takeuchi and Nagahama, 2002b). The charge carrier densities at the rock surface achieved under conditions such as in our experiment may be lower, but the measured values give an estimate, by order of magnitude, of the number of p-hole charge carriers available at the rock surface. 

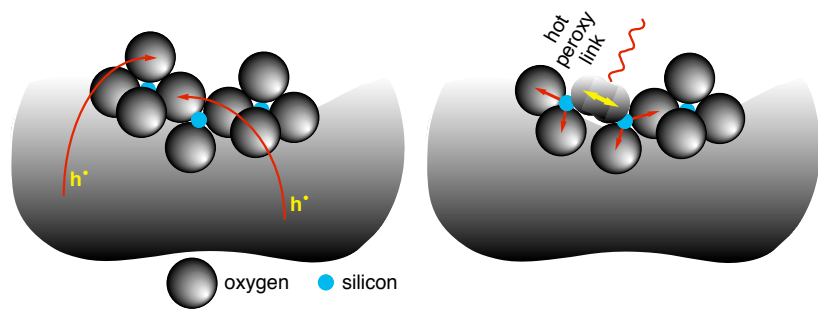

Fig. 5. Schematic representation of a mineral surface to illustrate the processes that may take place when p-holes (h) arrive at the surface (left). When the two p-holes recombine, recombination energy is released, leading to a vibrationally highly excited $\mathrm{O}-\mathrm{O}$ bond, which can de-excite radiatively by emitting IR photons characteristic of transitions the energy levels of the $\mathrm{O}-\mathrm{O}$ bond, and nonradiatively by channeling energy into neighboring bonds (right).

Of particular interest to the IR emission is the fact that it costs energy to break a peroxy bond. This energy is expended in the stressed rock volume in the form of mechanical work dispensed during plastic deformation. If the p-holes recombine at the surface to restitute peroxy bonds, some of this energy will be regained. However, this recombination energy will be deposited into the newly formed $\mathrm{O}^{-}-\mathrm{O}^{-}$bonds, causing them to be "born" in a vibrationally highly excited state.

To estimate the energies involved we need to know at least approximately the $\mathrm{O}-\mathrm{O}$ bond energy. The energy needed to photodissociate a peroxy link in fused silica is relatively high, $9.4 \mathrm{eV}$ (Nishikawa et al., 1990). By contrast, the activation energy to thermally split a peroxy bond is much lower, on the order of $2.4 \mathrm{eV}$ (Freund et al., 1993). The large difference is due to the fact that, during photodissociation, electrons must be excited across the large band gap at the same $\mathrm{k}$-value in reciprocal space. By contrast, thermal bond breakup can be achieved through excitation of vibrational modes irrespective of the k-value in reciprocal space. When a bond breaks during the passage of a dislocation, i.e. during mechanical deformation, we expect the energy required to be similar to that of thermal break-up, i.e. around $2.4 \mathrm{eV}$. In addition we note that the energy of the peroxy bond as well as the $\mathrm{O}-\mathrm{O}$ bond distance depend only weakly on the surrounding, i.e. they are closely the same for peroxy anions in the matrix of $\mathrm{MgO}$ and for peroxy links in matrix of fused silica. Without loss of generality we can extend this argument to silicate minerals and, by extension, to rocks (Freund, 2003). Hence, we adopt a value around $2.4 \mathrm{eV}$ as the maximum energy that can become available when p-holes recombine at our rock surface to form PHPs.

In Fig. 5 we represent the rock surface by three cornerlinked $\mathrm{SiO}_{4}$ tetrahedra, two of which terminate with nonbonded oxygens. Typical distances between adjacent $\mathrm{O}^{2-}$ are on the order of $2.8 \AA$. On the left we show two p-holes arriving at the surface and settling on two adjacent oxygen anions changing them from $\mathrm{O}^{2-}$ to $\mathrm{O}^{-}$. On the right we show these two $\mathrm{O}^{-}$snapping together to form the very short, $\sim 1.5 \AA, \mathrm{O}^{-}-\mathrm{O}^{-}$bond characteristic of peroxy links (Ricci et al., 2001).

If an energy up to $2.4 \mathrm{eV}$ is released during p-hole recombination, the new $\mathrm{O}^{-}-\mathrm{O}^{-}$bond will be "born" in a vibrationally highly excited state. Due to its high frequency, such an excited state will be largely decoupled from the thermal vibrations of the surrounding matrix. To dissipate the excess energy two decay channels are available: (i) radiative decay by emitting photons at the characteristic energies of transitions within the O-O vibrational manifold or (ii) nonradiative decay by channeling energy onto neighboring $\mathrm{Si}-\mathrm{O}$ and Al-O bonds. Those neighboring bonds in turn become excited and will emit at their characteristic vibrational frequencies.

As mentioned above the room temperature emission spectrum such as shown in Fig. 2 arises from downward transitions of vibrational modes from levels that are thermally excited at the temperature of $300 \mathrm{~K}$. The probability to populate the levels $\mathrm{E}_{n}$ above the ground state $\mathrm{E}_{o}$ is given by a Boltzmann distribution, $\exp \left[-\left(\mathrm{E}_{n}-\mathrm{E}_{0}\right) / \mathrm{kT}\right]$ where $\mathrm{k}$ is the Boltzmann constant and $\mathrm{T}$ the absolute temperature. We are interested in the IR emission around $1000 \mathrm{~cm}^{-1}$ or $10 \mu \mathrm{m}$. In this wavenumber or wavelength range the energy levels are separated by $\approx 100 \mathrm{meV}$. However, the mean thermal energy available at $300 \mathrm{~K}, \mathrm{kT}_{300 \mathrm{~K}}$, is $\approx 25 \mathrm{meV}$. Hence, the probability to populate the first excited level $\mathrm{n}=1$ in the $10-12 \mu \mathrm{m}$ region, is $\mathrm{e}^{-4} \approx 2 \times 10^{-2}$ or $\approx 2 \%$. To populate the second excited level, $\mathrm{n}=2, \approx 200 \mathrm{meV}$ above $\mathrm{E}_{0}$, the probability drops to $\mathrm{e}^{-8} \approx 10^{-4}$ or $\approx 0.02 \%$ etc. Therefore, at thermal equilibrium at $300 \mathrm{~K}$, vibrational levels $\mathrm{n}=2$ and higher are sparsely populated. In other words, nearly all IR intensity emitted at $300 \mathrm{~K}$ is due to downward transitions from the $\mathrm{n}=1$ level to the $\mathrm{n}=0$ ground level. If higher vibrational levels can be excited by some other, non-thermal process, downward transitions will occur between the higher levels, for instance from $\mathrm{n}=2$ to $\mathrm{n}=1$ or $\mathrm{n}=3$ to $\mathrm{n}=2$, etc. Those emission bands are called "hot bands".

Remarkable about the difference spectra in Fig. 3b is that they clearly show narrow emission bands appearing already at the very beginning of loading. In particular we point to the three narrow bands toward the right. The band at $930 \mathrm{~cm}^{-1}(10.75 \mu \mathrm{m})$ is consistent with the fundamental stretching mode of the $\mathrm{O}^{-}-\mathrm{O}^{-}$bond, arising from $\mathrm{n}=1$ to $\mathrm{n}=0$ transitions of peroxy links. The energy of this transition for $\mathrm{O}_{3} \mathrm{Si} /{ }^{\mathrm{OO}} \backslash \mathrm{SiO}_{3}$ in amorphous $\mathrm{SiO}_{2}$ has been determined by high level quantum-mechanical calculations to be $920-930 \mathrm{~cm}^{-1}(10.75-10.87 \mu \mathrm{m})$ (Ricci et al., 2001). The energies of "hot" transitions, from $n=2$ to $n=1$ and from $n=3$ to $n=2$, have not yet been calculated, However, they are expected to lie at slightly lower wavenumbers (longer wavelength) due to the asymmetry of the potential describing the $\mathrm{O}-\mathrm{O}$ bond.

The energy $\mathrm{V}$ as a function of interatomic distance $\mathrm{r}$ of a diatomic oscillator such as $\mathrm{O}-\mathrm{O}$ can be described by a Morse 
potential, $\mathrm{V}(\mathrm{r})=\mathrm{D}_{c}\left\{1-\exp \left[-\alpha\left(\mathrm{r}-\mathrm{r}_{0}\right) / \mathrm{r}_{0}\right]\right\}$, where $\mathrm{D}_{c}$ is the dissociation energy, $\mathrm{r}_{0}$ the equilibrium distance, and $\alpha$ an adjustable constant. The Morse potential is a parabola that opens asymmetrically to one side. The eigenvalues, which can be obtained by solving the Schrödinger equation for the system, show a sequence of energy levels ever more narrowly spaced the higher the level $\mathrm{n}$ of vibrational excitation. If the narrow band at $930 \mathrm{~cm}^{-1}$ in Figs. $3 \mathrm{a}, \mathrm{b}$ is the fundamental arising from $\mathrm{n}=1$ to $\mathrm{n}=0$ transitions, then the narrow bands at $870 \mathrm{~cm}^{-1}(11.5 \mu \mathrm{m})$, and $810 \mathrm{~cm}^{-1}(12.35 \mu \mathrm{m})$ are consistent with "hot" bands arising from $n=2$ to $n=1$ and $n=3$ to $n=2$ transitions respectively. In other words, these bands come from suprathermal transitions and suggest emissions that involve vibrationally excited states higher than $n=2$.

The intensity evolution of the three bands at $930 \mathrm{~cm}^{-1}$ $(10.75 \mu \mathrm{m}), 870 \mathrm{~cm}^{-1}(11.5 \mu \mathrm{m})$, and $810 \mathrm{~cm}^{-1}(12.35 \mu \mathrm{m})$ is plotted in Fig. 6 for the first three 2-min intervals after beginning of loading. The bands at $810 \mathrm{~cm}^{-1}(12.35 \mu \mathrm{m})$ and $870 \mathrm{~cm}^{-1}(11.5 \mu \mathrm{m})$, which we assign to hot transitions, exhibit high intensities in the beginning. Later the fundamental at $930 \mathrm{~cm}^{-1}(10.75 \mu \mathrm{m})$ gains intensity in relative and absolute terms, while the hot bands seem to merge.

The narrow bands in the $1000-1200 \mathrm{~cm}^{-1}(8.3-10 \mu \mathrm{m})$ range in Fig. $3 \mathrm{~b}$ display a similar intensity evolution as a function of time and load. They are consistent with the concept shown in Fig. 5 depicting (on the right) that the vibrationally excited $\mathrm{O}^{-}-\mathrm{O}^{-}$bond channels energy onto its Si-O neighbors, probably through combination with phonon modes. This causes those neighboring bonds to become excited and emit at their own characteristic frequencies.

In Fig. 4 we integrated the excess intensity emitted over the course of the experiment, from the beginning of loading to failure of the rock. The excess intensity curve exhibits narrow maxima around 1150 and $1300 \mathrm{~cm}^{-1}(7.7$ and $8.7 \mu \mathrm{m}$, respectively) but minima close to where the $300 \mathrm{~K}$ spectrum has its broad emission maxima. This suggests that the energy gained by p-hole recombination at the surface is primarily used to excite local oscillators. While they give rise primarily to non-thermal emissions, they do not excite the pool of 3-dimensionally coupled lattice modes, i.e. they do not "heat" the surface. This is consistent with the statement made above that vibrationally highly excited levels are largely decoupled from the lattice modes that vibrate at their fundamental frequencies at $300 \mathrm{~K}$. As a result the excess energy deposited during p-hole recombination into the newly born $\mathrm{O}^{-}-\mathrm{O}^{-}$bonds is mainly radiated off as narrow-band IR photons at $930 \mathrm{~cm}^{-1}(10.75 \mu \mathrm{m}), 870 \mathrm{~cm}^{-1}(11.5 \mu \mathrm{m})$, and $810 \mathrm{~cm}^{-1}(12.35 \mu \mathrm{m})$ and others at lower wavenumbers or longer wavelengths, which we did not measure in our experiment. A fraction of this energy is used to selectively excite next-nearest neighbor $\mathrm{Si}-\mathrm{O}$ and $\mathrm{Al}-\mathrm{O}$ bonds.

As this process continues, the next-nearest neighbor $\mathrm{Si}-\mathrm{O}$ and $\mathrm{Al}-\mathrm{O}$ bonds will in turn "kick" their neighbors and transfer energy to them so that they transition from their ground state $n=0$ to the first excited state $n=1$. In other words, the
Anorthosite

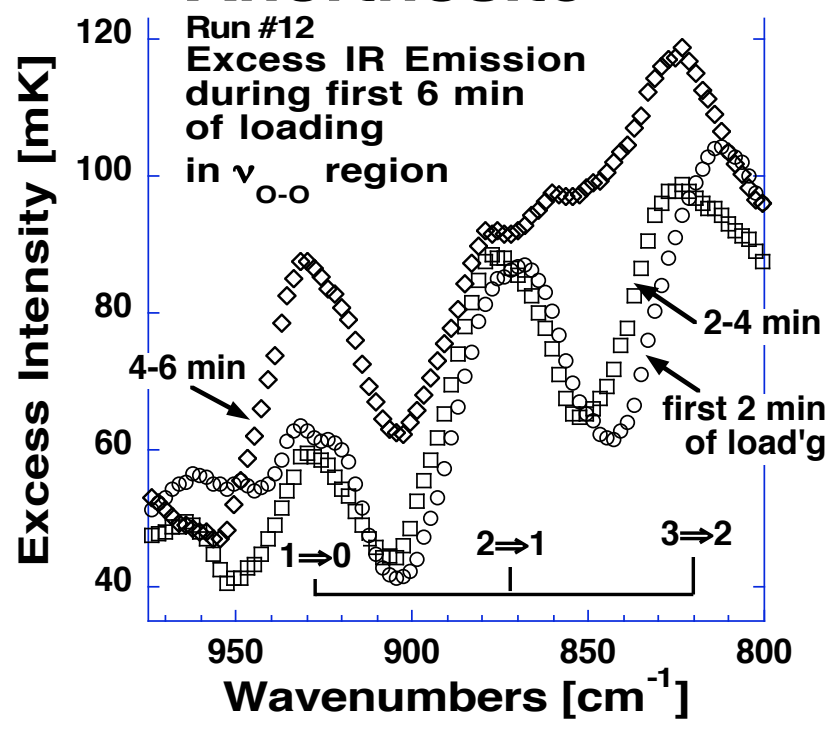

Fig. 6. Evolution of the IR emission bands in the spectral range expected to contain the O-O fundamental and "hot bands" during the first 6 min of loading, broken down in 2 min intervals.

energy deposited into local O-O vibrations will eventually flow into the 3-dimensionally coupled lattice vibrations, i.e. thermalize and thereby cause the overall energy, kT, in a thin surface layer to increase. As Figs. 3a, b indicate, this thermalization and increase in $\mathrm{kT}$ are most pronounced shortly before failure of the rock.

Hence, the observations presented here support our proposition that the emission spectrum of the anorthosite rock during stressing is at first dominated by non-thermal processes, giving rise to the series of narrow emission bands that include "hot" bands. The "hot" bands can be described as "stimulated IR luminescence" due to exothermal p-hole recombination at the surface. Later, as more and more p-holes arrive at the rock surface and recombine, the energy deposited into the O-O bonds begins to spread out and thermalize. This causes an overall, albeit small, increase in kT, i.e. an increase in the actual temperature of a thin surface layer.

To estimate how much energy can be radiated during phole recombination we need to know (i) how many p-holes arrive at the surface and (ii) how much energy is released per p-hole recombination event.

(i) For a surface across a dielectric contrast from $\varepsilon=10$ to $\varepsilon=1$ theory predicts the build-up of a surface potential on the order of $+0.4 \mathrm{~V}$ (King and Freund, 1984). Pulse-like values as high as $+12 \mathrm{~V}$ to $+17 \mathrm{~V}$ have been observed experimentally during crack formation (Enomoto et al., 1993; Freund et al., 2004). Steady state surface potentials reach values up to $+0.1 \mathrm{~V}$ to $+1.5 \mathrm{~V}$ depending on the geometry of the capacitive sensor, implying charge carrier densities of $\approx 10^{-5}$ Coulomb m$^{-2}$, 
equivalent to $\approx 10^{13}$ charges $\mathrm{m}^{-2}$ (Freund, 2002; Freund et al., 2006; Takeuchi et al., 2006; Takeuchi and Nagahama, 2002a, b).

(ii) We can estimate how many p-hole recombination events are needed to produce a $0.15 \mathrm{~K}$ increase of radiation temperature. The activation energy for breaking a peroxy bond is $\approx 2.4 \mathrm{eV}$ (Freund, 2003). If this energy were to be fully regained during p-hole recombination, each recombination event would release $2.4 \mathrm{eV}$, equivalent in terms of thermal energy $\mathrm{kT}$ to $\approx 10000 \mathrm{~K}$. This means that $\approx 10^{5}$ recombination events spread over a surface area of $20 \mathrm{~cm}^{2}$ (the size of our emitting surface) would suffice to increase the radiative temperature by $0.1 \mathrm{~K}$.

Our emitting surface of $20 \mathrm{~cm}^{2}$ contains $\approx 10^{16} \mathrm{O}^{2-}$ anions. Accepting a charge carrier density of $\approx 10^{-5}$ Coulomb m ${ }^{-2}$ or $\approx 10^{13}$ charges $\mathrm{m}^{-2}$ (Takeuchi and Nagahama, 2002b), such a surface of $20 \mathrm{~cm}^{2}$ will reach a surface potential of $1 \mathrm{~V}$ when $\approx 10^{10} \mathrm{p}$-holes have arrived. Since we estimated that as few as $\approx 10^{5}$ recombination events per unit time are needed to increase the radiative temperature of our emitting surface by $0.1 \mathrm{~K}$, only a very small fraction of the p-holes, which reach the surface, $\approx 10^{-5}$, need to participate at any time in the IR emission process.

Such an order-of-magnitude estimate gives us confidence that the proposed mechanism for the observed increase in radiative temperature lies within the limit of our basic assumptions. We note that the rock surface, which emitted the IR radiation in our experiment, was smooth. If it had been rougher by a geometric factor of about 10 , the radiative IR flux would probably have increased by approximately the same factor to an equivalent temperature around $2 \mathrm{~K}$, closer to the $2-4^{\circ} \mathrm{C}$ temperature increases reported for the "thermal anomalies" before major earthquakes.

\section{Conclusions}

We have presented here just one experiment conducted under specific laboratory conditions with a block of monomineralic anorthosite. Our paper necessarily leaves many questions unaddressed. However, we have demonstrated that, by stressing a small subvolume of the rock far away from the emitting surface, the IR emission changes with respect to both, spectral composition and intensity. The changes are consistent with a fundamental process, never before described, that involves vibrationally highly excited states of $\mathrm{O}-\mathrm{O}$ bonds at the rock surface. The most convincing indicator of such a process is the appearance of distinct narrow band emissions at the beginning of our experiment. Subsequently, as more and more energy is deposited into the surface layer through the recombination of more p-holes, an overall temperature increase occurs, presumably due to thermalization of the vibrationally excited $\mathrm{O}-\mathrm{O}$ states.
It is reasonable to assume that this energy, which first causes localized vibrationally excited states and then heats up the surface through thermalization, can be transferred across the rock-air interface to the air. Such a secondary or tertiary process would be consistent with the suggestions made by a number of authors that the "thermal anomalies" as derived from satellite data arise in the near-ground air (Dey and Singh, 2003; Parnell, 2002; Tronin, 2002; Tronin et al., 2004).

When we apply stress over $40 \mathrm{~cm}$ away from the emitting rock surface and observe within $40 \mathrm{~s}$ or less changes in the IR emission, we can say with confidence that both, the IR intensity and IR spectrum, are consistent with (i) the flow of p-hole charge carriers from the stressed rock volume to the emitting surface and (ii) an exothermal recombination of p-holes to form positive hole pairs, PHP. It is consistent with a radiative decay of the vibrationally excited $\mathrm{O}-\mathrm{O}$ bonds and with the channeling of some of their excess energy onto neighboring $\mathrm{Si}-\mathrm{O}$ and $\mathrm{Al}-\mathrm{O}$ bonds and eventual thermalization. The surface that emits the IR radiation is clearly too far from the stressed rock volume for frictional heat to reach the surface within such a short time.

Obviously, the areas of the Earth where "thermal anomalies" are observed are much more complex that the surface of the rock sample that we studied in the laboratory. Their surfaces are formed mainly of sedimentary deposits, soil and sand, rarely bare rocks. Preliminary laboratory studies (unpublished) have provided evidence that p-holes are capable of propagating through layers of soil and sand separating two blocks of rock and through layers of water.

The experiment described here and its interpretation suggest that p-holes provide a physically plausible mechanism to transport energy rapidly over macroscopic distances, from deep within the Earth's crust to the surface. At least a part of this energy is released at the surface following conversion into IR photons of specific wavelengths. Though further experiments are obviously needed to address these and many other questions raised by the study presented here, it appears probable that the recombination of p-hole charge carriers at the Earth's surface is the primary driver behind the pre-earthquake "thermal anomalies" identified in satellite images.

Acknowledgements. This work would not have been possible without support from Z. Wan and his coworkers Y. Zhang and Q. Zhang, ICESS, University of California at Santa Barbara, who brought their BOMEN radiospectrometer and other radiometric equipment three times to our laboratory. They helped us perform the experiments but do not necessarily subscribe to our interpretation of the results. We thank Y. Fei, Geophysical Laboratory, Carnegie Institution of Washington, and M. Jhabvala, NASA Goddard Space Flight Center, for help during the early phase of this project. We thank two anonymous reviewers for their thoughtful comments. We acknowledge financial support by a grant from the NASA Ames Research Center Director's Discretionary Fund. B. W. S. Lau was supported by a grant from the National Geospatial 
Agency (NGA). A. Takeuchi acknowledges support from the Japan Society for the Promotion of Science (JSPS) for Young Scientists.

Edited by: J.-P. Valet

\section{References}

Batllo, F., LeRoy, R. C., Parvin, K., Freund, F., and Freund, M. $\mathrm{M}$.: Positive hole centers in $\mathrm{MgO}$ - correlation between magnetic susceptibility, dielectric anomalies and electric conductivity, J. Appl. Phys., 69, 6031-6033, 1991.

Brady, B. T. and Rowell, G. A.: Laboratory investigation of the electrodynamics of rock fracture, Nature, 321, 488-492, 1986.

Chadha, R. K., Pandey, A. P., and Kuempel, H. J.: Search for earthquake precursors in well water levels in a localized seismically active area of Reservoir Triggered Earthquakes in India, Geophys. Res. Lett., 30, 69-71, 2003.

Cui, C., Zhang, J., Xiao, Q., Liu, Q., Luo, D. J., and Lu, Q.: Monitoring the thermal IR anomaly of Zhangbei earthquake precursor by satellite Remote sensing technique, paper presented at ACRS, 1999.

Dey, S. and Singh, R. P.: Surface latent heat flux as an earthquake precursor, Nat. Hazards Earth Syst. Sci., 3, 749-755, 2003, http://www.nat-hazards-earth-syst-sci.net/3/749/2003/.

Dickinson, J. T., Jensen, L. C., McKay, M. R., and Freund, F.: The emission of atoms and molecules accompanying fracture of single-crystal magnesium oxide, J. Vac. Sci. Technol., 4, 16481652, 1986.

Edwards, A. H. and Fowler, W. B.: Theory of the peroxy-radical defect in a-SiO2., Phys. Rev. B Solid State, 26, 6649-6660, 1982.

Enomoto, Y., Akai, M., Hashimoto, H., Mori, S., and Asabe, Y.: Exoelectron emission: Possible relation to seismic geoelectromagnetic activities as a microscopic aspect in geotribology, Wear, 168, 135-142, 1993.

Freund, F.: Conversion of dissolved "water" into molecular hydrogen and peroxy linkages, J. Non-Crystalline Solids, 71, 195-202, 1985.

Freund, F.: Charge generation and propagation in rocks, J. Geodynamics, 33, 545-572, 2002.

Freund, F., Freund, M. M., and Batllo, F.: Critical review of electrical conductivity measurements and charge distribution analysis of MgO, J. Geophys. Res., 98, 22 209-22 229, 1993.

Freund, F. T., Jhabvala, M., La, A., Shu, P., Tsay, S., Ouzounov, D., and Fei, Y.: Mid-infrared luminescence observed during rock deformation, paper presented at Spring Meeting, Amer. Geophys. Union, Washington, D.C., 2002a.

Freund, F. T., Ouzounov, D., Freund, M. M., Wan, Z., Zhang, Q., Zhang, Y., Jhabvala, M., La, A., McClare, M., Velle, A. M., Fei, Y., and Tsay, S.: Mid-Infrared radiation, electric charges and acoustic emission during rock deformation, paper presented at Fall Meeting, Amer. Geophys. Union, Washington, D.C., $2002 \mathrm{~b}$.

Freund, F. and Wengeler, H.: The infrared spectrum of $\mathrm{OH}-$ compensated defect sites in $\mathrm{C}$-doped $\mathrm{MgO}$ and $\mathrm{CaO}$ single crystals, J. Phys. Chem. Solids, 43, 129-145, 1982.

Freund, F. T.: On the electrical conductivity structure of the stable continental crust, J. Geodynamics, 35, 353-388, 2003.

Freund, F. T., Ouzounov, D., Wan, Z., Zhang, Y., Zhang, Q., Post, R., Keefner, J., Mellon, J., and Al-Manaseer, A.: Stimulated IR emission from the surface of rocks during deformation, paper presented at American Geophysical Union, Fall Meeting 2003, AGU, San Francisco, CA, 2003.

Freund, F. T., Takeuchi, A., Lau, B. W. S., Post, R., Keefner, J., Mellon, J., and Al-Manaseer, A.: Stress-induced changes in the electrical conductivity of igneous rocks and the generation of ground currents, Terrestrial, Atmospheric and Oceanic Sciences (TAO), 15, 437-468, 2004.

Freund, F. T., Takeuchi, A., and Lau, B. W.: Electric currents streaming out of stressed igneous rocks - A step towards understanding pre-earthquake low frequency EM emissions, Phys. Chem. Earth, 31, 389-396, 2006.

Gornyi, V. I., Salman, A. G., Tronin, A. A., and Shilin, B. B.: The Earth's outgoing IR radiation as an indicator of seismic activity, Proc. Acad. Sci. USSR, 301, 67-69, 1988.

Ingrin, J. and Skogby, H.: Hydrogen in nominally anhydrous uppermantle minerals: concentration levels and implications, European J. Mineralogy, 12, 543-570, 2000.

Johnson, J. R., Hörz, F., Lucey, P. G., and Christensen, P. R.: Thermal infrared spectroscopy of experimentally shocked anorthosite and pyroxenite: Implications for remote sensing of Mars, J. Geophys. Res., 107, 5073-5086, 2002.

King, B. V. and Freund, F.: Surface charges and subsurface space charge distribution in magnesium oxide containing dissolved traces of water., Phys. Rev., B29, 5814-5824, 1984.

Li, Z.-L., Becker, F., Stoll, M., Wan, Z., and Zhang, Y.: Channel selection for soil spectrum reconstruction in $8-13 \mu \mathrm{m}$ region, J. Geophys. Res., 104, 22 271-22 286, 1999.

Lockner, D.: The role of acoustic emission in the study of rock fracture, Int. J. Rock Mechanics Mining Sci., 30, 883-899, 1993.

Martens, R., Gentsch, H., and Freund, F.: Hydrogen release during the thermal decomposition of magnesium hydroxide to magnesium oxide, J. Catalysis, 44, 366-372, 1976.

Miguel, M. C., Vespignani, A., Zapperi, S., Weiss, J., and Grass, J.-R.: Intermittent dislocation flow in viscoplastic deformation, Nature, 410, 667-671, 2001.

Moore, D. E. and Lockner, D. A.: The role of microcracking in shear-fracture propagation in granite, J. Struct. Geol., 17, 95114, 1995.

Ohnaka, M.: A shear failure strength law of rock in the brittleplastic transition regime, Geophys. Res. Lett., 22, 25-28, 1995.

Parnell, J.: Fluid Seeps at Continental Margins: towards an Integrated Plumbing System,Geofluids, 2, 57-65, 2002.

Pulinets, S. A, Ouzounov, D., Ciraolo, L., et al.: Thermal, atmospheric and ionospheric anomalies around the time of the Colima M7.8 earthquake of 21 January 2003, Ann. Geophys., 24, 835849, 2006, http://www.ann-geophys.net/24/835/2006/.

Qiang, Z.-J., Xu, X.-D., and Dian, C.-D.: Thermal infrared anomaly - precursor of impending earthquakes, Chinese Sci. Bull., 36, 319-323, 1991.

Qiang, Z. J., Xu, X. D., and Dian, C. G.: Abnormal infrared thermal satellite-forewarning of earthquakes, Chinese Sci. Bull., 35, 1324-1327, 1990.

Quing, Z., Xiu-Deng, X., and Chang-Gong, D.: Thermal infrared anomaly- precursor of impending earthquakes, Chinese Sci. Bull., 36, 319-323, 1991.

Ricci, D., Pacchioni, G., Szymanski, M. A., Shluger, A. L., and Stoneham, A. M.: Modeling disorder in amorphous silica with embedded clusters: The peroxy bridge defect center, Phys. Rev. 
B, 64, 224 104-224 108, 2001.

Rowell, G. A., Brady, B. T., Yoder, L. P., and Hanson, D. R.: Precursors of laboratory rock failure, in: Fracture Mechnanics for Ceramics, Rocks, and Concrete, edited by: Freiman, S. W. and Fuller, E. R., pp. 196-220, ASTM, Philadelphia, PA, 1981.

Srivastav, S. K., Dangwal, M., Bhattachary, A., and Reddy, P. R.: Satellite data reveals pre-earthquake thermal anomalies in Killari area, Maharashtra, Current Sci., 72, 880-884, 1997.

Takeuchi, A., Lau, B. W., and Freund, F. T.: Current and surface potential induced by stress-activated positive holes in igneous rocks, Phys. Chem. Earth, 31, 240-247, 2006.

Takeuchi, A. and Nagahama, H.: Interpretation of charging on fracture or frictional slip surface of rocks, Phys. Earth Planet. Inter., 130, 285-291, 2002a.

Takeuchi, A. and Nagahama, H.: Surface charging mechanism and scaling law related to earthquakes, J. Atmos. Electricity, 22, 183190, 2002b.

Tronin, A. A. (Ed.): Satellite thermal survey application for earthquake prediction, 717-746 pp., Terra Sci. Publ., Tokyo, Japan, 1999.

Tronin, A. A.: Thermal satellite data for earthquake research, paper presented at IGARSS 2000, IEEE 2000 international geoscience and remote sensing symposium. Taking the pulse of the planet: the role of remote sensing in managing the environment, IEEE, Honolulu, HI, 2000.
Tronin, A. A.: Atmosphere-lithosphere coupling: Thermal anomalies on the Earth surface in seismic processes, in: SeismoElectromagnetics: Lithosphere-Atmosphere-Ionosphere Coupling, edited by: Hayakawa, M. and Molchanov, O. A., 173-176, Terra Scientific Publ., Tokyo, 2002.

Tronin, A. A., Molchanov, O. A., and Biagi, P. F.: Thermal anomalies and well observations in Kamchatka, Int. J. Rem. Sens., 25, 2649-2655, 2004.

Wan, Z., Snyder, W., and Zhang, Y.: Validation of land-surface temperature retrieval from space, paper presented at IGARSS '96: Remote Sensing for a Sustainable Future, Geoscience and Remote Sensing Symposium, IGARSS, Lincoln, NE, 1996.

Warwick, J. W., Stoker, C., and Meyer, T. R.: Radio emission associated with rock fracture: Possible application to the great Chilean earthquake of May 22, 1960, J. Geophys. Res., 87, 2851-2859, 1982.

Wilkins, R. W. T. and Sabine, W.: Water contents of some nominally anhydrous silicates, Amer. Mineral., 58, 508-516, 1973.

Yoshida, S. and Ogawa, T.: Electromagnetic emissions from dry and wet granite associated with acoustic emissions, J. Geophys, Res., 109, B09204, doi:10.1029/2004JB003092, 2004. 